\section{IUCrJ}

ISSN 2052-2525

NEUTRON|SYNCHROTRON

\title{
Neutron crystallography aids in drug design
}

\author{
M. P. Blakeley*
}

Large-Scale Structures Group, Institut Laue-Langevin, 71 Avenue des Martyrs, Grenoble, 38000, France. ${ }^{*}$ Correspondence e-mail: blakeleym@ill.fr

Neutron crystallography is an important complementary technique to X-ray crystallography since it provides details of the hydrogen $(\mathrm{H})$ atom and proton $\left(\mathrm{H}^{+}\right)$positions in biological molecules. Furthermore, as neutrons (of the energies used for crystallographic experiments) are a non-destructive probe, the resulting structures are free from radiation damage even at room temperature (Blakeley et al., 2015). Knowledge of H-bonding networks, water molecule orientations and protonation states, along with details of hydrophobic and electrostatic interactions, can prove vital towards a better understanding of many biological processes, such as enzyme mechanisms (Casadei et al., 2014; Vandavasi et al., 2016) and ligand binding (Howard et al., 2016), and can help guide structure-based drug design (Huang et al., 2014).

The first neutron crystallography study of a clinically used drug bound to its target was that of acetazolamide (AZM), a sulfonamide, which binds with high affinity to human carbonic anhydrase isoform II (Fisher et al., 2012). Human carbonic anhydrases (hCA) are zinc metalloenzymes that catalyze the interconversion of $\mathrm{CO}_{2}$ and $\mathrm{H}_{2} \mathrm{O}$ to $\mathrm{HCO}_{3}{ }^{-}$ and $\mathrm{H}^{+}$, an important reaction for many physiological processes including respiration, fluid secretion and $\mathrm{pH}$ regulation. As such, hCA isoforms are prominent clinical targets for treating various diseases, such as glaucoma and epilepsy. hCA II is one of 12 catalytically active isoforms and, due to sequence conservation between them, substantial offtarget binding to other isoforms occurs, reducing drug efficiency and causing side effects. Hence, there is a need to design effective hCA isoform-specific drugs. Over $400 \mathrm{X}$-ray crystal structures have been determined for hCA II, with around half of these in complex with inhibitors, yet despite the large amount of structural data available, key details regarding the $\mathrm{H}$-atom positions of the protein and solvent and the charged state of the bound inhibitor were missing. The room-temperature neutron structure of hCA II in complex with AZM at $2.0 \AA$ resolution revealed that the charged state of bound AZM was the anionic form, along with details of hydration, $\mathrm{H}$ bonding and hydrophobic interactions between AZM and hCA II (Fisher et al., 2012).

In this issue of IUCrJ, McKenna and co-workers (Aggarwal et al., 2016) describe X-ray and neutron crystallography studies of hCA II in complex with a second sulfonamide inhibitor, methazolamide (MZM) - a methyl derivative of AZM that is preferred clinically for reasons such as greater stability, longer half life, lower dose and fewer side effects. They report the room-temperature neutron structure of hCA II in complex with MZM at 2.2 $\AA$ resolution, revealing the inhibitor is also bound in the anionic form, along with details of hydration, $\mathrm{H}$ bonding and hydrophobic interactions between MZM and hCA II. They then compare the binding of the two inhibitors in the room-temperature neutron structures, and in particular show that more water molecules are displaced from the active site by MZM than AZM, relative to the neutron structure of unbound hCA II at $2.0 \AA$ resolution (Fisher et al., 2011). Since the overall binding affinity $\left(K_{\mathrm{i}}\right)$ for both of the drugs against hCA II is similar $(\sim 10 \mathrm{n} M)$, they discuss the balance between enthalpic and entropic contributions towards drug binding, and using molecular dynamics simulations suggest that in the case of MZM, hydrophobic forces perhaps compensate for the loss of an extensive H-bonding network.

In recent years, a growing number of neutron structures have been deposited in the Protein Data Bank, including a number of other examples of enzyme-drug complexes, such as the recent structures of HIV-1 protease with the clinical inhibitors amprenavir (Weber et al., 2013) and darunavir (Gerlits et al., 2016), and the structure of farnesyl pyrophosphate synthase with the osteoporosis drug risedronate bound (Yokoyama et al., 2015). Although the overall number of neutron structures is still relatively small, there 


\section{scientific commentaries}

are a growing number of examples for which neutron crystallography has provided the answers to questions that have remained elusive using other techniques.

\section{References}

Aggarwal, M., Kovalevsky, A. Y., Velazquez, H., Fisher, S. Z., Smith, J. C. \& McKenna, R. (2016). IUCrJ, 3, 319-325.

Blakeley, M. P., Hasnain, S. S. \& Antonyuk, S. V. (2015). IUCrJ, 2 , 464-474.

Casadei, C. M., Gumiero, A., Metcalfe, C. L., Murphy, E. J., Basran, J., Concilio, M. G., Teixeira, S. C. M., Schrader, T. E., Fielding, A. J., Ostermann, A., Blakeley, M. P., Raven, E. L. \& Moody, P. C. E. (2014). Science, 345, 193-197.

Fisher, S. Z., Aggarwal, M., Kovalevsky, A. Y., Silverman, D. N. \& McKenna, R. (2012). J. Am. Chem. Soc. 134, 14726-14729.

Fisher, Z., Kovalevsky, A. Y., Mustyakimov, M., Silverman, D. N., McKenna, R. \& Langan, P. (2011). Biochemistry, 50, 9421-9423.
Gerlits, O., Wymore, T., Das, A., Shen, C. H., Parks, J. M., Smith, J. C., Weiss, K., Keen, D. A., Blakeley, M. P., Louis, J. M., Langan, P., Weber, I. \& Kovalevsky, A. Y. (2016). Angew. Chem. Int. Ed. 55, 4924-4927.

Howard, E. I., Guillot, B., Blakeley, M. P., Haertlein, M., Moulin, M., Mitschler, A., Cousido-Siah, A., Fadel, F., Valsecchi, W. M., Tomizaki, T., Petrova, T., Claudot, J. \& Podjarny, A. (2016). IUCrJ, 3, 115-126.

Huang, G. Y., Gerlits, O., Blakeley, M. P., Sankaran, B., Kovalevsky, A. Y. \& Kim, C. (2014). Biochemistry, 53, 6725-6727.

Vandavasi, V. G., Weiss, K. L., Cooper, J. B., Erskine, P. T., Tomanicek, S. J., Ostermann, A., Schrader, T. E., Ginell, S. L. \& Coates, L. (2016). J. Med. Chem. 59, 474-479.

Weber, I. T., Waltman, M. J., Mustyakimov, M., Blakeley, M. P., Keen, D. A., Ghosh, A. K., Langan, P. \& Kovalevsky, A. Y. (2013). J. Med. Chem. 56, 5631-5635.

Yokoyama, T., Mizuguchi, M., Ostermann, A., Kusaka, K., Niimura, N., Schrader, T. E. \& Tanaka, I. (2015). J. Med. Chem. 58, 75497556. 